\title{
Biomechanical evaluation of an integrated fixation cage during fatigue loading: a human cadaver study
}

\author{
Vivek Palepu, PhD, ${ }^{1}$ Jonathan H. Peck, ME, ${ }^{2}$ David D. Simon, PhD, ${ }^{1}$ Melvin D. Helgeson, $M D,{ }^{3}$ and \\ Srinidhi Nagaraja, $\mathrm{PhD}^{1}$
}

\begin{abstract}
'Division of Applied Mechanics, Office of Science and Engineering Laboratories, and 2Division of Orthopedic Devices, Office of Device Evaluation, Center for Devices and Radiological Health, US Food and Drug Administration, Silver Spring; and ${ }^{3}$ Department of Orthopaedics, Walter Reed National Military Medical Center, Bethesda, Maryland
\end{abstract}
OBJECTIVE Lumbar cages with integrated fixation screws offer a low-profile alternative to a standard cage with ante- rior supplemental fixation. However, the mechanical stability of integrated fixation cages (IFCs) compared with a cage with anterior plate fixation under fatigue loading has not been investigated. The purpose of this study was to compare the biomechanical stability of a screw-based IFC with a standard cage coupled with that of an anterior plate under fatigue loading.

METHODS Eighteen functional spinal units were implanted with either a 4-screw IFC or an anterior plate and cage $(A P+C)$ without integrated fixation. Flexibility testing was conducted in flexion-extension (FE), lateral bending (LB), and axial rotation (AR) on intact spines, immediately after device implantation, and post-fatigue up to 20,000 cycles of FE loading. Stability parameters such as range of motion (ROM) and lax zone (LZ) for each loading mode were compared between the 2 constructs at multiple stages of testing. In addition, construct loosening was quantified by subtracting post-instrumentation ROM from post-fatigue ROM.

RESULTS IFC and AP+C configurations exhibited similar stability (ROM and LZ) at every stage of testing in FE ( $p \geq$ $0.33)$ and $L B(p \geq 0.23)$ motions. In $A R$, however, IFCs had decreased ROM compared with AP+C constructs at pre-fatigue $(p=0.07)$ and at all post-fatigue time points $(p \leq 0.05)$. LZ followed a trend similar to that of ROM in AR. ROM increased toward intact motion during fatigue cycling for AP+C and IFC implants. IFC specimens remained significantly ( $p$ $<0.01$ ) more rigid than specimens in the intact condition during fatigue for each loading mode, whereas $A P+C$ construct motion did not differ significantly $(p \geq 0.37)$ in FE and LB and was significantly greater $(p<0.01)$ in AR motion compared with intact specimens after fatigue. Weak to moderate correlations $\left(R^{2} \leq 56 \%\right)$ were observed between T-scores and construct loosening, with lower T-scores leading to decreased stability after fatigue testing.

CONCLUSIONS These data indicate that a 4-screw IFC design provides fixation similar to that provided by an $A P+C$ construct in FE and LB during fatigue testing and better stability in AR motion.

https://thejns.org/doi/abs/10.3171/2016.9.SPINE16650

KEY WORDS integrated fixation cage; anterior plate; cadaver; fatigue; functional spinal unit; range of motion

$\mathrm{D}$ ISC degeneration is a leading cause of spinal instability resulting in low-back pain. ${ }^{18,25}$ Pain from disc degeneration is the second most common reason for physician visits in the United States and results in economic costs exceeding 100 billion dollars per year.,22 Spinal fusion remains the gold standard surgical treatment option, with a reported $200 \%$ increase in the number of lumbar fusion surgeries over the past decade. ${ }^{7,21}$ Spinal fusion procedures often involve inserting an intervertebral body fusion device (cage) into the disc space and further stabilizing the motion segment with supplemental fixation to promote biological fusion. Integrated fixation cages (IFCs) incorporate screws or other bone anchors into the cage and often fit completely within the disc space, giving them a lower profile than traditional anterior plates and potentially reducing the exposure necessary for implantation. These design advantages may reduce complications, surgical costs, and morbidity.

ABBREVIATIONS $A P=$ anterior plate; $A P+C=$ anterior plate and cage; $A R=$ axial rotation; $D X A=$ dual-energy $x$-ray absorptiometry; $F E=$ flexion-extension; $F S U=$ functional spinal unit; IFC = integrated fixation cage; $L B=$ lateral bending; $L Z$ = lax zone; $R O M=$ range of motion.

SUBMITTED June 6, 2016. ACCEPTED September 19, 2016.

INCLUDE WHEN CITING Published online January 27, 2017; DOI: 10.3171/2016.9.SPINE16650. 
Quasi-static biomechanical testing can provide insight into the initial postoperative mechanical stability of spinal fusion devices. Our previous study found no differences between pullout forces for IFC screws and anterior plate screws, indicating that IFC and anterior plate screws exhibited similar fixation behavior during static testing. ${ }^{23}$ However, these implants are subjected to repetitive loading in vivo, and thus the fixation strength of the devices cannot be fully evaluated with a static pullout study. The dynamic in vivo environment presents challenges to the stability of spinal constructs, particularly at the bone-implant interface, where screw loosening, subsidence, and migration may occur over time. Fatigue testing of these constructs provides an advantage over quasi-static testing as it has the ability to assess implant performance in a simulated postoperative environment. This type of mechanical testing is not frequently performed, likely due to the complexities of longer-duration testing, such as tissue degradation observed in spines at ambient temperatures. ${ }^{30}$ Early fatigue studies focused on the stability of spinal rods, plates, and screws..$^{5,14,15,20,24}$ More recently, there have been studies investigating interbody cages and facet fixation., $6,10,11$, $13,26,27,29$ One of these studies found that spines implanted with cage and pedicle screw instrumentation maintained stability after 5000 cycles of fatigue testing. ${ }^{27}$ Although this study provided insights into the stability of traditional cages, IFCs have screws incorporated into the design to afford additional stability. Previous research studies have focused on the initial stability of IFCs; however, there has been no study to investigate the mechanical performance of IFCs over time. Therefore, the objective of this study was to compare the stability of lumbar IFCs with that of a more traditional anterior plate and cage construct under fatigue loading.

\section{Methods}

\section{Specimen Preparation}

Nine fresh-frozen human cadaver specimens, 7 male and 3 female (mean age $74 \pm 8$ years), were procured from accredited tissue processing institutions (National Disease Research Interchange and Maryland State Anatomy Board). The medical history of each donor was reviewed to exclude trauma, malignancy, previous implantations, or metabolic disease that might otherwise compromise the mechanical properties of the lumbar spine. Each specimen was radiographically screened to exclude osteolysis, fractures, or other abnormalities. After careful removal of fat and musculature, the lumbar spine was scanned using dual-energy x-ray absorptiometry (DXA, Hologic) in the anterioposterior direction to assess bone mineral density. The average bone mineral density and $\mathrm{T}$-score for these cadaver specimens were $0.93 \pm 0.17 \mathrm{mg} / \mathrm{cm}^{3}$ and $-1.0 \pm$ 1.6, respectively (Table 1). The L2-3 and L4 -5 functional spinal units (FSUs) were isolated from the spinal column and were prepared for mechanical testing by potting both ends in rapidly curing epoxy and allowing it to cure at room temperature.

\section{Implant Designs}

This study compared the stability of IFC devices to
TABLE 1. Cadaver specimen demographic and DXA information

\begin{tabular}{ccccc}
\hline Specimen No. & Sex & Age (yrs) & T-Score & BMD $\left(\mathrm{g} / \mathrm{cm}^{2}\right)$ \\
\hline 1 & M & 69 & 1.2 & 1.176 \\
\hline 2 & M & 72 & 1.5 & 1.206 \\
\hline 3 & M & 61 & -2.1 & 0.813 \\
\hline 4 & M & 71 & 0.1 & 1.053 \\
\hline 5 & M & 85 & -1.1 & 0.923 \\
\hline 6 & M & 81 & -1.6 & 0.865 \\
\hline 7 & M & 70 & -1.8 & 0.841 \\
\hline 8 & F & 70 & -2.4 & 0.782 \\
\hline 9 & F & 83 & -2.9 & 0.724 \\
\hline
\end{tabular}

$\mathrm{BMD}=$ bone mineral density.

that of cages supplemented with anterior plates (APs). APs were chosen as supplemental fixation for the control group since fixation features of IFCs are effectively intended to replace the function of APs. In addition, pedicle screw systems have been shown to be significantly stiffer compared with IFC devices and other anterior-only lumbar constructs. ${ }^{2,17,28}$ Therefore, the use of pedicle screws in both IFC and control groups would have resulted in very rigid constructs and prevented understanding the impact of integrated fixation features alone.

AP and IFC devices were designed incorporating common features of commercially available implants. APs and screws were manufactured from titanium 6Al-4 V alloy (Fig. 1A), and IFCs were fabricated from PEEK-OPTIMA (Invibio) (Fig. 1B). AP and IFC implant sizes were based on preliminary radiographic screening of the cadaver FSUs. To conduct the screening, micro-CT (Scanco Medical) was performed on all FSUs at 51- $\mu$ m voxel resolution. A board-certified surgeon reviewed micro-CT images and radiographs to determine the optimal size of the implant based on the intervertebral disc height, lordosis, and anterior-posterior and lateral vertebral endplate measurements. An AP having 4 screw holes for fixation was chosen with the following dimensions: $37 \mathrm{~mm}$ length, 26 $\mathrm{mm}$ width, and $3 \mathrm{~mm}$ thickness.

The IFCs were designed to have 2 footprints $(26 \mathrm{~mm}$ depth $\times 32 \mathrm{~mm}$ width, $27 \mathrm{~mm}$ depth $\times 37 \mathrm{~mm}$ width). Each footprint had 3 options for lordosis $\left(0^{\circ} / 8^{\circ} / 12^{\circ}\right)$ and 3 different heights $(12 / 14 / 16 \mathrm{~mm})$ with 4 screw holes oriented at $45^{\circ}$ ( 2 superior and 2 inferior) for fixation. This resulted in a total of 18 different cage sizes available for this study (Table 2) with a range of sizes similar to that offered in
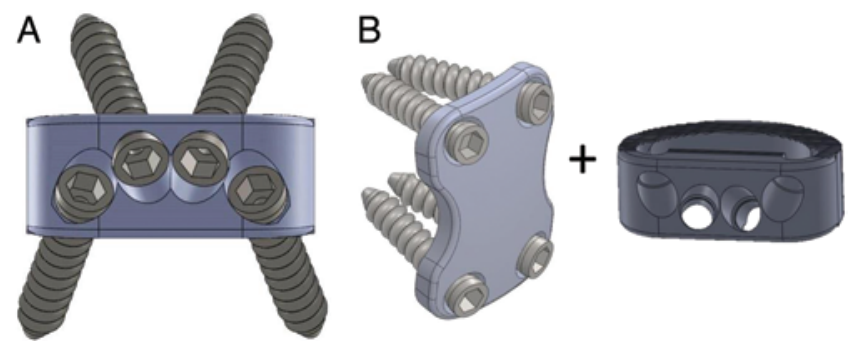

FIG. 1. Integrated fixation cage (A) and anterior plate and cage (B) designs used for the fatigue testing. Figure is available in color online only. 
TABLE 2. ALIF cage sizes available for study

\begin{tabular}{cccc}
\hline Depth $(\mathrm{mm})$ & Width $(\mathrm{mm})$ & Height $(\mathrm{mm})$ & Lordosis $\left(^{\circ}\right)$ \\
\hline 26 & 32 & $12,14,16$ & 0 \\
\hline 26 & 32 & $12,14,16$ & 8 \\
\hline 26 & 32 & $12,14,16$ & 12 \\
\hline 27 & 37 & $12,14,16$ & 0 \\
\hline 27 & 37 & $12,14,16$ & 8 \\
\hline 27 & 37 & $12,14,16$ & 12 \\
\hline
\end{tabular}

commercially available anterior lumbar interbody fusion (ALIF) cages. Screws used in both AP and IFC implants had a length of $25 \mathrm{~mm}(5.5 \mathrm{~mm}$ outer diameter, $3.5 \mathrm{~mm}$ inner diameter, and $2.1 \mathrm{~mm}$ screw pitch). This screw is representative of the bone screws commonly employed in both lumbar APs and IFCs.

\section{Implantation Procedure}

FSUs were reconstructed using an anterior approach by a board-certified spine surgeon. In accordance with standard surgical technique, anterior discectomy was performed including removal of the anterior longitudinal ligament, anterior annulus, nucleus, and cartilaginous endplates, using rongeurs, curettes, and Cobb elevators. After discectomy was performed, a lamina spreader was used to distract the endplates with optimal tension. Next, an interbody cage size was selected based on the distracted space, which was measured using digital calipers. Surgical placement of the interbody cage was flush with the anterior lip of the endplate. This procedure was consistently followed for all FSUs. For the IFC group, screws were added through the cage into the superior and inferior endplates. For FSUs in the anterior plate and cage $(\mathrm{AP}+\mathrm{C})$ group, screws were inserted through the plate and secured to the anterior column. Implantations were performed in descending order of bone mineral density of the donor spine, with the IFC being alternated between $\mathrm{L} 2-3$ and $\mathrm{L} 4-5$ while the $\mathrm{AP}+\mathrm{C}$ was placed in the complementary FSU.

\section{Mechanical Testing}

Flexibility testing was performed on all the FSUs for the following conditions: 1) intact spine; 2) implanted spine, immediately after implantation (pre-fatigue); 3) implanted spine, after 5000 fatigue cycles; 4) implanted spine, after 12,500 fatigue cycles; and 5) implanted spine, after 20,000 fatigue cycles.

The protocol for mechanical flexibility testing of the spines followed the methods used in previous studies. ${ }^{1,4,17}$ A spine simulator (MTS) (Fig. 2) was used for applying pure and unconstrained moments on the FSUs to generate the following loading modes: flexion and extension (FE), right and left lateral bending (LB), and right and left axial rotation (AR). An Optotrak Certus motion measurement system (Northern Digital) was used to track the spinal motion of the superior and inferior vertebrae during spinal loading. Three loading cycles of $\pm 7.5 \mathrm{Nm}$ were applied in each loading direction. The first 2 cycles served as preconditioning cycles to account for viscoelastic effects with data collection on the third cycle. ROM was calculated as the total angular displacement of the third loading cycle for each motion mode. In addition, the lax zone (LZ) was quantified by extrapolating a line fit of torque-angle curve (i.e., stiffness from 5-7 Nm) to zero torque. LZ is another stability parameter that describes the region of ligamentous laxity and is described further in previously published literature. ${ }^{8,12}$ The fatigue loading protocol of reconstructed specimens consisted of initial FE loading to \pm $3 \mathrm{Nm}$ at $1 \mathrm{~Hz}$ for the first 5000 cycles and then increased to $\pm 5 \mathrm{Nm}$ until 20,000 cycles. This loading protocol provided multiple physiological load levels to assess construct stability. All the specimens were wrapped in gauze, and phosphate-buffered saline was sprayed periodically to keep the specimen hydrated during testing.

\section{Data Analysis}

A paired t-test was used to determine significant differences $(p \leq 0.05)$ in ROM and LZ for each loading mode (FE, LB, and AR) between IFC and $\mathrm{AP}+\mathrm{C}$ constructs for the following conditions: intact, pre-fatigue, and post$5,000,12,500$, and 20,000 cycles of FE fatigue. Repeated-measures analysis of variance (Minitab) was used to compare ROM and LZ between intact, pre-fatigue, and fatigue time points for each construct. In addition, construct loosening was determined by subtracting the pre-fatigue ROM of the implanted spine for a given specimen from ROM after 20,000 cycles. A linear regression analysis was performed between construct loosening and T-score of the FSU for both AP+C and IFC constructs.

\section{Results}

Table 3 provides mean ROM and standard deviations for $\mathrm{AP}+\mathrm{C}$ and IFC in FE, $\mathrm{LB}$, and $\mathrm{AR}$ at each stage of testing. In FE, no differences were observed in ROM and LZ between AP+C and IFC configurations $(p \geq 0.33)$ for the intact condition, pre-fatigue, or post-5000, 12,500, and 20,000 cycles (Fig. 3 and Table 4). Within AP+C and IFC constructs, FE ROM was similar at 5000 cycles but more flexible at 12,500 and 20,000 cycles $(p \leq 0.01)$ compared with pre-fatigue ROM. As with FE, there were no differences $(p \geq 0.23)$ in stability parameters (ROM and $L Z)$ between the 2 constructs at any stage of testing in LB (Fig. 4). For AP+C constructs, LB ROM became greater than pre-fatigue values only after 20,000 cycles $(p=0.05)$. The LZ under LB motion also increased during fatigue cycling but remained similar to pre-fatigue $\mathrm{LZ}$ for all stages of testing ( $p>0.20)$. For IFC specimens, LB motion became significantly greater after 12,500 cycles compared with pre-fatigue $(\mathrm{p}<0.04)$. Intact AR ROM and LZ were significantly greater in IFC compared with $\mathrm{AP}+\mathrm{C}$ specimens ( $\mathrm{p}<0.01)$. However, AR motion and LZ immediately after implantation (i.e., pre-fatigue) for IFCs was lower ( $\mathrm{p} \leq$ $0.07)$ than $\mathrm{AP}+\mathrm{C}$. In addition, IFC constructs maintained significantly reduced $(\mathrm{p} \leq 0.05)$ AR motion compared with $\mathrm{AP}+\mathrm{C}$ in all post-fatigue time points (Fig. 5). LZ under AR loading followed a similar trend in all post-fatigue time points. AR ROM and LZ were significantly greater compared with pre-fatigue values for $\mathrm{AP}+\mathrm{C}$ constructs after 12,500 cycles $(\mathrm{p}<0.01)$. For IFC constructs, ROM 


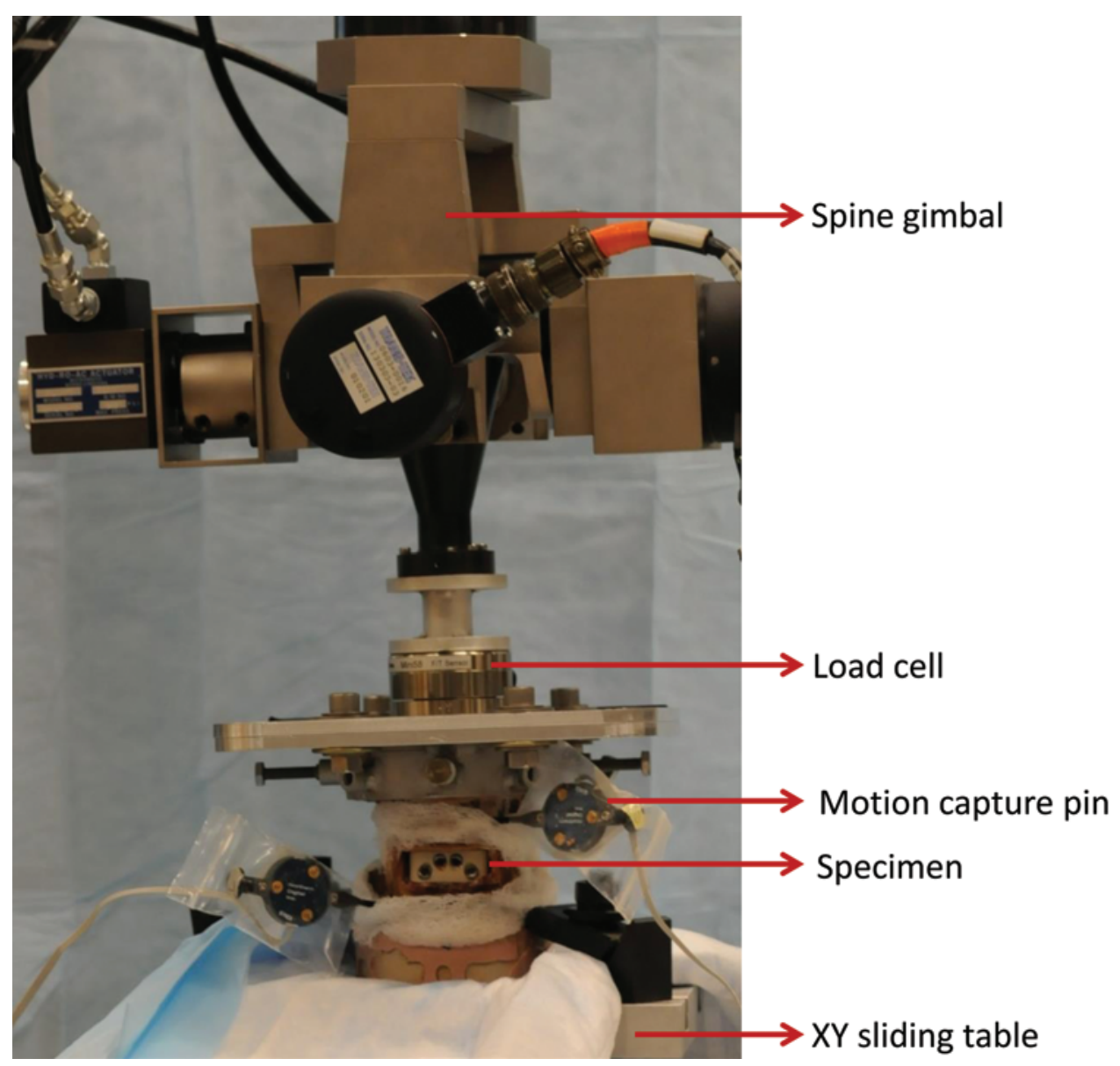

FIG. 2. Experimental setup of reconstructed spine specimen connected to a sliding $X Y$ table at the bottom and spine gimbal with 6 -axis load cell on top. Figure is available in color online only.

and LZ were not significantly different from pre-fatigue results at 5000 and 12,500 cycles $(p>0.20)$, but the differences were close to significance at 20,000 cycles $(p<0.16)$ under AR motions.

Table 5 provides a statistical comparison between stages of testing for $\mathrm{FE}, \mathrm{LB}$, and $\mathrm{AR}$ motions. $\mathrm{AP}+\mathrm{C}$ constructs significantly reduced FE ROM in pre-fatigue testing ( $\mathrm{p}<$ $0.01)$ and after $5000(\mathrm{p}<0.01)$ and 12,500 $(\mathrm{p}=0.04)$ cycles but had similar motion $(p=0.37)$ after 20,000 cycles compared with the intact condition. IFC constructs reduced FE motion significantly in pre-fatigue and all post-fatigue time points $(\mathrm{p}<0.01)$ compared with testing in the in-

TABLE 3. Range of motion for AP+C and IFC constructs at each stage of testing for each loading mode

\begin{tabular}{|c|c|c|c|c|c|}
\hline \multirow[b]{2}{*}{ Variable } & \multirow[b]{2}{*}{ Intact } & \multirow[b]{2}{*}{ Pre-Fatigue } & \multicolumn{3}{|c|}{ Post-Fatigue } \\
\hline & & & $5 \mathrm{~K}$ & $12.5 \mathrm{~K}$ & $20 \mathrm{~K}$ \\
\hline \multicolumn{6}{|c|}{ Flexion-extension } \\
\hline$A P+C$ & $6.9 \pm 2.0$ & $2.5 \pm 1.4$ & $4.0 \pm 2.3$ & $5.1 \pm 3.1$ & $5.8 \pm 3.6$ \\
\hline IFC & $7.8 \pm 1.9$ & $2.6 \pm 1.7$ & $3.5 \pm 2.1$ & $4.5 \pm 2.7$ & $4.9 \pm 2.8$ \\
\hline \multicolumn{6}{|c|}{ Lateral bending } \\
\hline$A P+C$ & $7.6 \pm 2.8$ & $4.7 \pm 2.5$ & $5.5 \pm 3.1$ & $6.0 \pm 3.1$ & $6.5 \pm 3.5$ \\
\hline IFC & $8.2 \pm 2.0$ & $3.3 \pm 1.9$ & $4.0 \pm 2.2$ & $4.7 \pm 2.7$ & $5.1 \pm 2.9$ \\
\hline \multicolumn{6}{|l|}{ Axial rotation } \\
\hline$A P+C$ & $3.5 \pm 1.6$ & $2.8 \pm 1.8$ & $4.1 \pm 2.5$ & $4.6 \pm 2.7$ & $5.2 \pm 3.1$ \\
\hline IFC & $5.3 \pm 2.2$ & $1.4 \pm 1.0$ & $1.9 \pm 1.4$ & $2.5 \pm 1.7$ & $2.8 \pm 1.7$ \\
\hline
\end{tabular}

$\mathrm{AP}+\mathrm{C}=$ anterior plate + cage; $\mathrm{IFC}=$ integrated fixation cage.

Data are presented as mean values presented with standard deviations. Units of measure are degrees $\left(^{\circ}\right)$. 


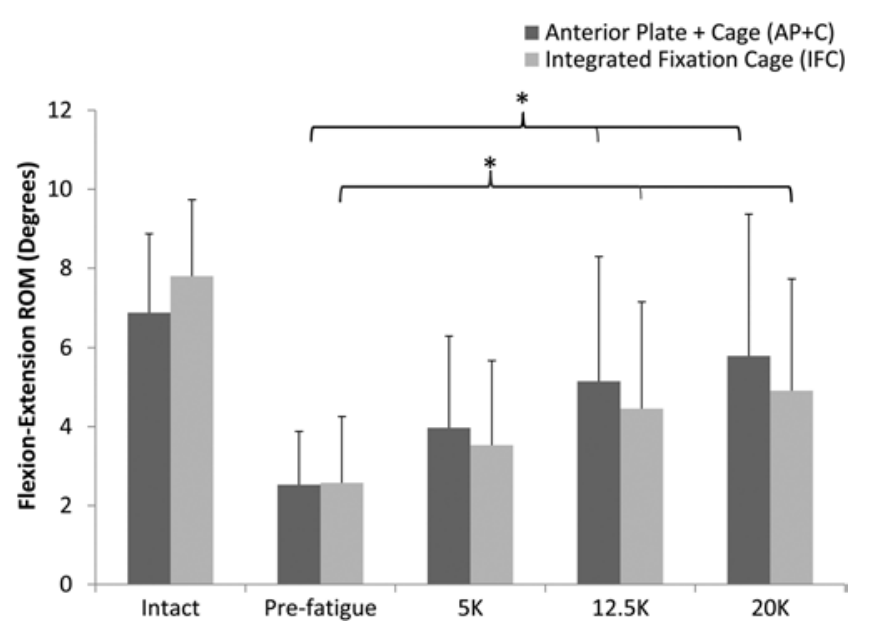

FIG. 3. Flexion-extension ROM for the intact and pre-fatigue conditions and after 5000, 12,500, and 20,000 cycles of fatigue loading for IFC and $\mathrm{AP}+\mathrm{C}$ constructs. The constructs exhibited similar behavior at all stages of testing. A significant increase in ROM occurred at $12.5 \mathrm{~K}$ and $20 \mathrm{~K}$ cycles $\left({ }^{*} p<0.007\right)$.

tact condition. AP+C constructs significantly reduced LB ROM in pre-fatigue testing $(\mathrm{p}<0.01)$ compared with the intact condition and maintained this rigidity only up to 5000 cycles of fatigue $(p=0.02)$. IFC constructs had significantly reduced LB motion in all time points compared with the intact condition $(\mathrm{p}<0.01)$. For $\mathrm{AP}+\mathrm{C}$ constructs, intact AR ROM was similar to pre-fatigue ROM; however, AR ROM after 20,000 cycles was significantly increased relative to intact AR ROM $(\mathrm{p}=0.01)$. In contrast, the IFC construct reduced AR motion significantly in pre-fatigue testing compared with the intact condition and maintained stability at all post-fatigue time points $(\mathrm{p}<0.01)$.

Regression analysis of construct loosening in all motions followed a similar trend where cadavers with reduced bone density possessed less stability after fatigue testing in both AP and IFC constructs. After fatigue testing, construct loosening in FE was significantly correlated $\left(\mathrm{R}^{2}=\right.$ $52 \%, \mathrm{p}=0.03$ ) to $\mathrm{T}$-scores in $\mathrm{AP}+\mathrm{C}$ specimens (Fig. 6). IFC specimens followed a similar trend but had a weaker correlation $\left(\mathrm{R}^{2}=24 \%, \mathrm{p}=0.18\right)$. Loosening in LB motion

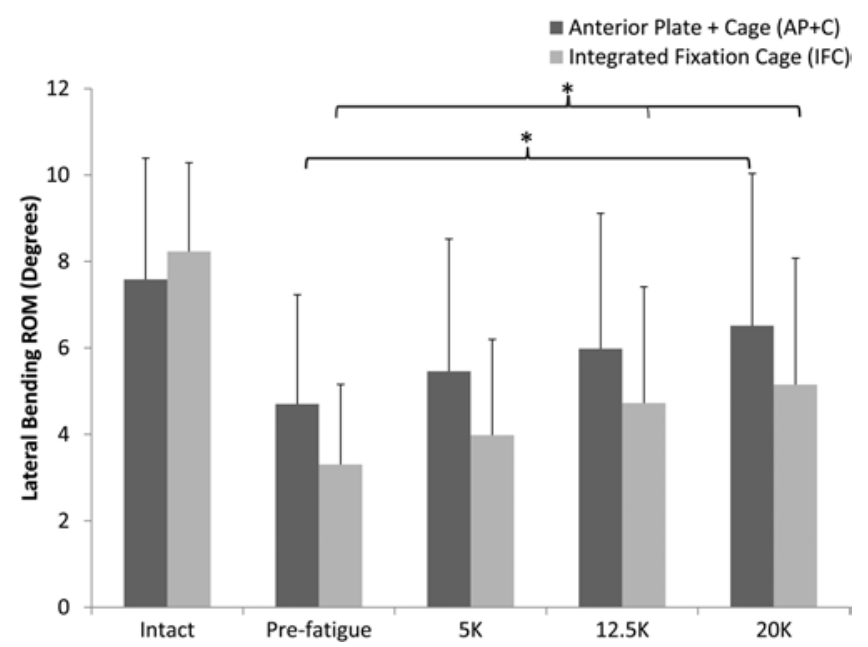

FIG. 4. Lateral bending ROM for the intact and pre-fatigue conditions and after 5000, 12,500, and 20,000 cycles of fatigue loading for IFC and $\mathrm{AP}+\mathrm{C}$ constructs. The constructs exhibited similar behavior at all stages of testing. A significant increase in ROM occurred at $12.5 \mathrm{~K}$ (IFC) and 20 $\mathrm{K}\left(\mathrm{AP}+\mathrm{C}\right.$ and IFC) cycles ( $\left.{ }^{*} \mathrm{p}<0.05\right)$.

was not correlated with T-scores in $\mathrm{AP}+\mathrm{C}$ specimens $\left(\mathrm{R}^{2}\right.$ $=10 \%, \mathrm{p}=0.40)$ but was close to significance in IFC specimens $\left(\mathrm{R}^{2}=31 \%, \mathrm{p}=0.12\right)$. Construct loosening in $\mathrm{AR}$ was weakly correlated $\left(\mathrm{R}^{2}=32 \%, \mathrm{p}=0.11\right)$ to T-scores in $\mathrm{AP}+\mathrm{C}$ specimens and significantly correlated $\left(\mathrm{R}^{2}=55 \%\right.$, $\mathrm{p}=0.02$ ) to T-scores in IFC specimens, with osteoporotic cadavers having less stability after fatigue testing.

\section{Discussion}

IFCs have been previously evaluated biomechanically using cadaver specimens. ${ }^{2,3,17,19,28}$ These studies demonstrated that IFCs have increased stability compared with cages or structural allograft alone, but the results were mixed when IFCs were compared with cages with pedicle screws. One study found similar stability between an IFC and a cage with pedicle screws, ${ }^{3}$ whereas others have found that IFCs were less stable in at least 1 motion mode compared with either a cage or structural graft supplemented by pedicle screws. ${ }^{2,17,28}$ These findings, however,

TABLE 4. Mean \pm standard deviations of lax zone in degrees for $A P+C$ and IFC constructs at each time point for each loading mode

\begin{tabular}{|c|c|c|c|c|c|}
\hline Variable & Intact & Pre-Fatigue & $5 \mathrm{~K}$ & $12.5 \mathrm{~K}$ & $20 \mathrm{~K}$ \\
\hline \multicolumn{6}{|c|}{ Flexion-extension } \\
\hline$A P+C$ & $5.4 \pm 1.7$ & $1.7 \pm 1.1$ & $3.0 \pm 2.1$ & $4.2 \pm 3.0$ & $4.7 \pm 3.4$ \\
\hline IFC & $6.3 \pm 1.7$ & $1.6 \pm 1.3$ & $2.2 \pm 1.8$ & $3.2 \pm 2.4$ & $3.6 \pm 2.5$ \\
\hline \multicolumn{6}{|c|}{ Lateral bending } \\
\hline$A P+C$ & $5.4 \pm 2.2$ & $2.8 \pm 2.3$ & $3.1 \pm 2.4$ & $3.6 \pm 2.8$ & $4.0 \pm 2.9$ \\
\hline IFC & $6.1 \pm 1.8$ & $1.6 \pm 1.3$ & $2.0 \pm 1.7$ & $2.7 \pm 2.2$ & $3.0 \pm 2.4$ \\
\hline \multicolumn{6}{|l|}{ Axial rotation } \\
\hline$A P+C$ & $2.0 \pm 1.4$ & $2.2 \pm 1.7$ & $3.0 \pm 2.3^{*}$ & $3.4 \pm 2.6$ & $4.0 \pm 2.8^{*}$ \\
\hline IFC & $3.5 \pm 1.8^{*}$ & $0.7 \pm 0.8$ & $1.0 \pm 1.3$ & $1.6 \pm 1.4$ & $1.7 \pm 1.4$ \\
\hline
\end{tabular}

* Significant differences between groups for the specified time point $(p \leq 0.04)$. 


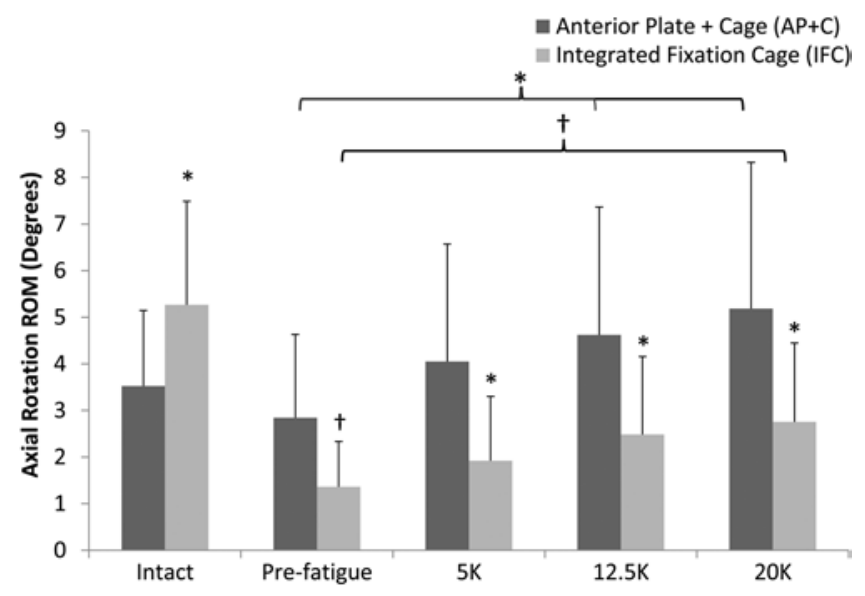

FIG. 5. Axial rotation ROM for the intact and pre-fatigue conditions and after $5000,12,500$, and 20,000 cycles of fatigue loading for IFC and $A P+C$ constructs. IFC constructs exhibited better performance than $A P+C$ constructs at all stages of testing. Significant increase in ROM occurred at $12.5 \mathrm{~K}(\mathrm{AP}+\mathrm{C})$ and $20 \mathrm{~K}\left(\mathrm{AP}+\mathrm{C}\right.$ and IFC) cycles. ${ }^{*} \mathrm{p}<0.05$, $+p=0.07$.

only provide insight into the initial stability of the IFC construct immediately after implantation. Therefore, the aim of this study was to evaluate IFC device stability in a fatigue environment that assesses loosening of the construct over time. We found that initial and post-fatigue stability for IFC implants were similar to results obtained with $\mathrm{AP}+\mathrm{C}$ constructs in FE and LB motions. We also found that IFCs exhibited better stability than AP+C constructs initially and after 20,000 cycles of fatigue in AR motion. Although our results are in good agreement with those of previous quasi-static studies for LB motion, previous studies concluded that IFCs provided significantly less stability in FE motion and similar stability in AR compared with anterior plate fixation with a cage or structural graft. ${ }^{2,17}$ One explanation for this discrepancy may be differences in IFC designs between studies. Previous studies used smaller diameter screws and/or fewer screws than our study, which may have resulted in less fixation strength of their IFC design when compared with AP+C. These dissimilar findings highlight the importance of IFC design in providing fixation strength that is comparable to that provided by $\mathrm{AP}+\mathrm{C}$ instrumentation. In addition, we suspect that the increased stability of the IFC compared with $\mathrm{AP}+\mathrm{C}$ in AR may be due to the location and orientation of the IFC screws within the intervertebral space providing a biomechanical advantage over anterior plates in AR motion.

Although flexibility increased toward intact motion during fatigue cycling for $\mathrm{AP}+\mathrm{C}$ and IFC implants, IFC specimens were significantly more stable in each loading mode than intact specimens after fatigue testing. In contrast, $\mathrm{AP}+\mathrm{C}$ construct motion was not significantly different in FE and LB motions and in fact was significantly greater in AR motion compared with intact after 20,000 cycles of fatigue. These data suggest that loosening as measured by ROM after fatigue loading is similar in the $\mathrm{AP}+\mathrm{C}$ and IFC configurations. However, IFC specimens may not loosen as much as $\mathrm{AP}+\mathrm{C}$ constructs in $\mathrm{AR}$ motion. Observations during fatigue testing showed that
TABLE 5. Results of statistical comparison of each time point for flexion-extension, lateral bending, and axial rotation motions

\begin{tabular}{|c|c|c|c|}
\hline \multirow[b]{2}{*}{ Comparison } & \multicolumn{3}{|c|}{$p$ Value } \\
\hline & $\mathrm{FE}$ & LB & AR \\
\hline \multicolumn{4}{|l|}{$A P+C$} \\
\hline \multicolumn{4}{|l|}{ Intact vs } \\
\hline Pre-fatigue & $<0.001$ & $<0.001$ & 0.527 \\
\hline $5 \mathrm{~K}$ & $<0.001$ & 0.016 & 0.741 \\
\hline $12.5 \mathrm{~K}$ & 0.044 & 0.110 & 0.108 \\
\hline $20 \mathrm{~K}$ & 0.369 & 0.459 & $\underline{0.005}$ \\
\hline \multicolumn{4}{|l|}{ Pre-fatigue vs } \\
\hline $5 \mathrm{~K}$ & 0.121 & 0.754 & 0.063 \\
\hline $12.5 \mathrm{~K}$ & $\leq 0.001$ & 0.280 & $\underline{0.002}$ \\
\hline $20 \mathrm{~K}$ & $\leq 0.001$ & 0.053 & $\leq \overline{0.001}$ \\
\hline \multicolumn{4}{|l|}{$5 \mathrm{~K}$ vs } \\
\hline $12.5 \mathrm{~K}$ & 0.284 & 0.921 & 0.685 \\
\hline $20 \mathrm{~K}$ & $\underline{0.029}$ & 0.468 & 0.090 \\
\hline \multicolumn{4}{|l|}{$12.5 \mathrm{~K}$ vs } \\
\hline $20 \mathrm{~K}$ & 0.803 & 0.914 & 0.689 \\
\hline \multicolumn{4}{|l|}{ IFC } \\
\hline \multicolumn{4}{|l|}{ Intact vs } \\
\hline Pre-fatigue & $<0.001$ & $<0.001$ & $<0.001$ \\
\hline $5 \mathrm{~K}$ & $<0.001$ & $<0.001$ & $<0.001$ \\
\hline $12.5 \mathrm{~K}$ & $<0.001$ & $<0.001$ & $<0.001$ \\
\hline $20 \mathrm{~K}$ & $<0.001$ & $<0.001$ & $<0.001$ \\
\hline \multicolumn{4}{|l|}{ Pre-fatigue vs } \\
\hline $5 \mathrm{~K}$ & 0.361 & 0.602 & 0.804 \\
\hline $12.5 \mathrm{~K}$ & $\underline{0.007}$ & 0.036 & 0.203 \\
\hline $20 \mathrm{~K}$ & $\leq 0.001$ & 0.003 & 0.070 \\
\hline \multicolumn{4}{|l|}{$5 \mathrm{~K}$ vs } \\
\hline $12.5 \mathrm{~K}$ & 0.392 & 0.519 & 0.803 \\
\hline $20 \mathrm{~K}$ & 0.078 & 0.118 & 0.487 \\
\hline \multicolumn{4}{|l|}{$12.5 \mathrm{~K}$ vs } \\
\hline $20 \mathrm{~K}$ & 0.899 & 0.892 & 0.983 \\
\hline
\end{tabular}

$\mathrm{AR}=$ axial rotation; $\mathrm{FE}=$ flexion-extension; $\mathrm{LB}=$ lateral bending

Boldface type indicates significantly lower ROM and the combination of boldface plus underlining indicates significantly greater ROM.

screw loosening of AP+Cs or IFCs was primarily responsible for the increase in ROM during fatigue loading. Interestingly, in the IFC specimens, loosening was observed more frequently for the medial screws than the lateral ones (Fig. 7). A recent study investigated the spatial variation in endplate thickness and trabecular bone volume fraction in vertebral bodies..$^{16}$ The authors found that the thickness of the ring apophysis was significantly greater than that of the central endplate region, and that central regions of the vertebral body had the lowest trabecular bone volume fraction compared with other regions. These data indicate that screw placement is an important design consideration for IFCs to maximize screw purchase. However, further studies are needed to confirm this study's qualitative observations of preferential medial screw loosening.

The cadavers used in this study possessed a wide range of bone mineral densities, resulting in T-scores from normal to osteoporotic, as defined by the World Health Organization. Regression analysis of these data showed that 

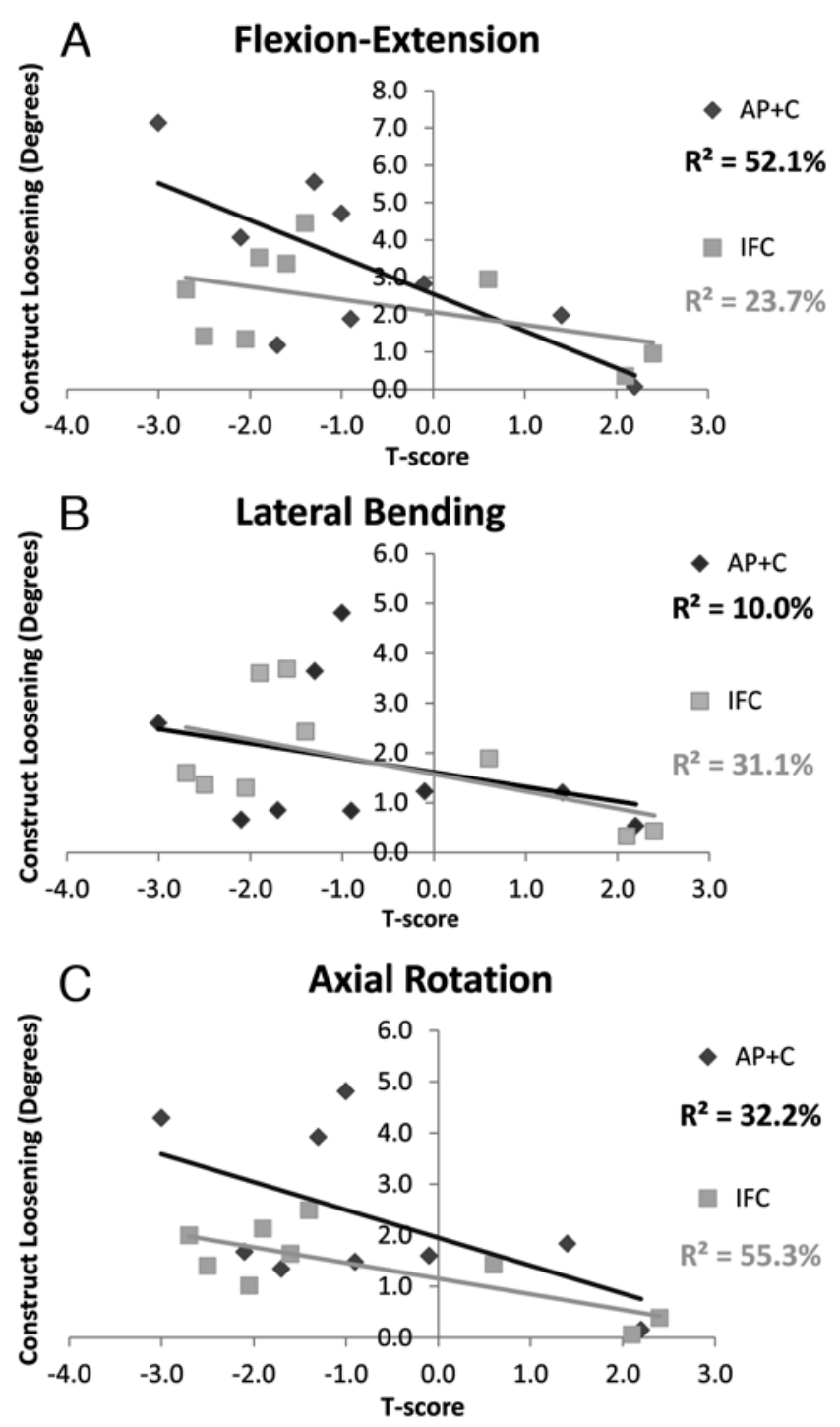

FIG. 6. Construct loosening after fatigue testing versus T-scores for IFC and $\mathrm{AP}+\mathrm{C}$ constructs. Linear regression values yielded correlations between $24 \%$ and $52 \%$ for FE (A), $10 \%-31 \%$ for LB (B), and $32 \%-55 \%$ for AR (C). Significance $(p<0.05)$ was found in FE for AP+C and in AR for IFC.

cadavers with lower T-scores had increased motion in post-fatigue testing. Although correlations were moderate, these data suggest that osteoporotic individuals who undergo implantation of either IFC or $\mathrm{AP}+\mathrm{C}$ constructs may fare worse than patients without osteoporosis. In fact, preliminary testing of 3 severely osteoporotic cadavers (T-scores less than -3.1) was stopped prematurely at 5000 cycles in both $\mathrm{AP}+\mathrm{C}$ and IFC constructs due to high instability. Although it is generally understood that osteoporotic patients are not good candidates for anterior-only approaches, this study confirmed that bone quality is an important consideration when selecting treatment options for patients with low-back pain.

There are some limitations that must be considered when interpreting these results. We compared the stability of an IFC design against a traditional cage coupled with an

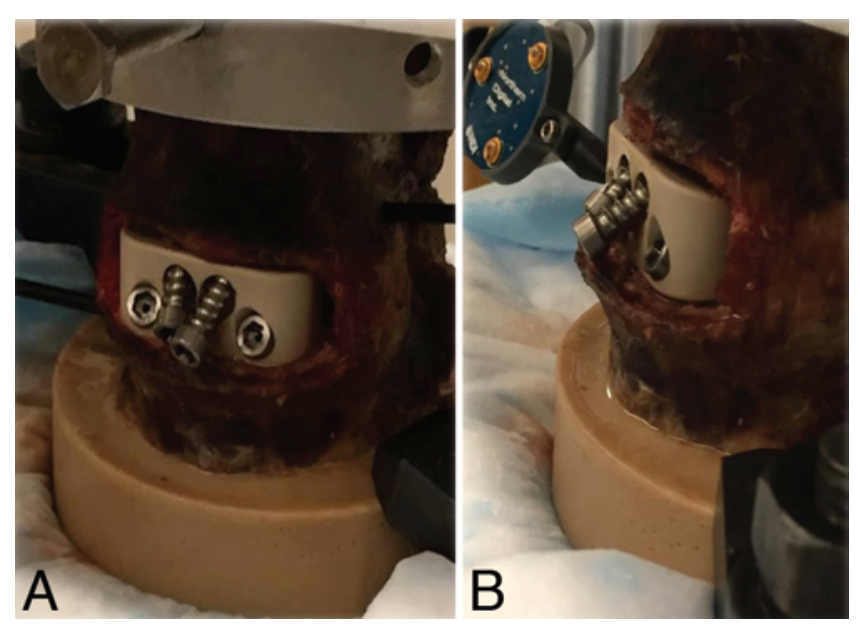

FIG. 7. Frontal (A) and lateral (B) views of IFC construct during fatigue testing. Medial screw loosening is visible in the IFC construct. Figure is available in color online only.

anterior plate. This is a reasonable comparison since integrated screws are used in IFC designs in an attempt to avoid the need for anterior plating. However, IFCs were not compared with other lumbar fixation methods such as pedicle screw fixation in this study; therefore, these results should not be extrapolated to conclude that IFCs alone are sufficient in cases where pedicle screws are necessary for adequate stability. In addition, intra- and inter-cadaver spine variability (e.g., differences in bone quality and ligament stiffness) can result in large standard deviations, which reduce the statistical power when attempting to determine differences between constructs. This is an inherent issue in cadaver studies, and appropriate selection of cadavers before testing is recommended to minimize variability.

\section{Conclusions}

Our cadaveric study was able to demonstrate comparable fixation strength between a 4-screw IFC design and a traditional cage with an AP under fatigue loading. Although these results suggest that IFCs may be a promising alternative to traditional cage and anterior plate constructs, it is important to confirm these biomechanical study results with functional clinical outcomes and radiographic findings, such as low loosening rates and successful fusion, particularly for unique IFC designs.

\section{Acknowledgments}

This work was supported by the FDA Office of Women's Health. The project was also supported in part by an appointment to the Oak Ridge Institute for Science and Education (ORISE) Research Participation Program at FDA/CDRH, administered by ORISE through an interagency agreement between the US Department of Energy and FDA/CDRH. We would like to thank Valerie Elliott at USDA for aid with DXA measurements, Srikanth Vasudevan for implant prototypes, and Hitesh Mehta and David Hwang for aid with study design and review.

\section{References}

1. Agarwal A, Palepu V, Agarwal AK, Goel VK, Yildirim ED: 
Biomechanical evaluation of an endplate-conformed polycaprolactone-hydroxyapatite intervertebral fusion graft and its comparison with a typical nonconformed cortical graft. J Biomech Eng 135:61005-61009, 2013

2. Beaubien BP, Freeman AL, Turner JL, Castro CA, Armstrong WD, Waugh LG, et al: Evaluation of a lumbar intervertebral spacer with integrated screws as a stand-alone fixation device. J Spinal Disord Tech 23:351-358, 2010

3. Cain CM, Schleicher P, Gerlach R, Pflugmacher R, Scholz M, Kandziora F: A new stand-alone anterior lumbar interbody fusion device: biomechanical comparison with established fixation techniques. Spine (Phila Pa 1976) 30:2631-2636, 2005

4. Cardoso MJ, Dmitriev AE, Helgeson M, Lehman RA, Kuklo TR, Rosner MK: Does superior-segment facet violation or laminectomy destabilize the adjacent level in lumbar transpedicular fixation? An in vitro human cadaveric assessment. Spine (Phila Pa 1976) 33:2868-2873, 2008

5. Chou WK, Chien A, Wang JL: Biomechanical analysis between PEEK and titanium screw-rods spinal construct subjected to fatigue loading. J Spinal Disord Tech 28:E121E125, 2015

6. Cook DJ, Yeager MS, Oh MY, Cheng BC: Lumbar intrafacet bone dowel fixation. Neurosurgery 76:470-478, 2015

7. Cowan JA Jr, Dimick JB, Wainess R, Upchurch GR Jr, Chandler WF, La Marca F: Changes in the utilization of spinal fusion in the United States. Neurosurgery 59:15-20, 2006

8. Crawford NR, Peles JD, Dickman CA: The spinal lax zone and neutral zone: measurement techniques and parameter comparisons. J Spinal Disord 11:416-429, 1998

9. Crow WT, Willis DR: Estimating cost of care for patients with acute low back pain: a retrospective review of patient records. J Am Osteopath Assoc 109:229-233, 2009

10. Ferrara LA, Secor JL, Jin BH, Wakefield A, Inceoglu S, Benzel EC: A biomechanical comparison of facet screw fixation and pedicle screw fixation: effects of short-term and long-term repetitive cycling. Spine (Phila Pa 1976) 28:12261234,2003

11. Freeman AL, Camisa WJ, Buttermann GR, Malcolm JR: Flexibility and fatigue evaluation of oblique as compared with anterior lumbar interbody cages with integrated endplate fixation. J Neurosurg Spine 24:54-59, 2016

12. Hanlon AD, Cook DJ, Yeager MS, Cheng BC: Quantitative analysis of the nonlinear displacement-load behavior of the lumbar spine. J Biomech Eng 136:081009, 2014

13. Heth JA, Hitchon PW, Goel VK, Rogge TN, Drake JS, Torner JC: A biomechanical comparison between anterior and transverse interbody fusion cages. Spine (Phila Pa 1976) 26:E261-E267, 2001

14. Hitchon PW, Goel VK, Rogge T, Grosland NM, Torner J: Biomechanical studies on two anterior thoracolumbar implants in cadaveric spines. Spine (Phila Pa 1976) 24:213218, 1999

15. Hitchon PW, Goel VK, Rogge TN, Torner JC, Dooris AP, Drake JS, et al: In vitro biomechanical analysis of three anterior thoracolumbar implants. J Neurosurg 93 (2 Suppl):252-258, 2000

16. Hulme PA, Boyd SK, Ferguson SJ: Regional variation in vertebral bone morphology and its contribution to vertebral fracture strength. Bone 41:946-957, 2007

17. Kornblum MB, Turner AW, Cornwall GB, Zatushevsky MA, Phillips FM: Biomechanical evaluation of stand-alone lumbar polyether-ether-ketone interbody cage with integrated screws. Spine J 13:77-84, 2013

18. Kuslich SD, Ulstrom CL, Michael CJ: The tissue origin of low back pain and sciatica: a report of pain response to tissue stimulation during operations on the lumbar spine using local anesthesia. Orthop Clin North Am 22:181-187, 1991

19. Kuzhupilly RR, Lieberman IH, McLain RF, Valdevit A, Kambic H, Richmond BJ: In vitro stability of FRA spacers with integrated crossed screws for anterior lumbar interbody fusion. Spine (Phila Pa 1976) 27:923-928, 2002

20. Lu WW, Zhu Q, Holmes AD, Luk KD, Zhong S, Leong JC: Loosening of sacral screw fixation under in vitro fatigue loading. J Orthop Res 18:808-814, 2000

21. Marawar S, Girardi FP, Sama AA, Ma Y, Gaber-Baylis LK, Besculides MC, et al: National trends in anterior cervical fusion procedures. Spine (Phila Pa 1976) 35:1454-1459, 2010

22. Modic MT, Ross JS: Lumbar degenerative disk disease. Radiology 245:43-61, 2007

23. Nagaraja S, Palepu V, Peck JH, Helgeson MD: Impact of screw location and endplate preparation on pullout strength for anterior plates and integrated fixation cages. Spine $\mathbf{J}$ 15:2425-2432, 2015

24. Pfeiffer M, Hoffman H, Goel VK, Weinstein JN, Griss P: In vitro testing of a new transpedicular stabilization technique. Eur Spine J 6:249-255, 1997

25. Schizas C, Kulik G, Kosmopoulos V: Disc degeneration: current surgical options. Eur Cell Mater 20:306-315, 2010

26. Trahan J, Morales E, Richter EO, Tender GC: The effects of lumbar facet dowels on joint stiffness: a biomechanical study. Ochsner J 14:44-50, 2014

27. Vadapalli S, Robon M, Biyani A, Sairyo K, Khandha A, Goel VK: Effect of lumbar interbody cage geometry on construct stability: a cadaveric study. Spine (Phila Pa 1976) 31:2189_ 2194, 2006

28. Voronov LI, Vastardis G, Zelenakova J, Carandang G, Havey RM, Waldorff EI, et al: Biomechanical characteristics of an integrated lumbar interbody fusion device. Int J Spine Surg 8:1, 2014

29. Wang ST, Goel VK, Fu CY, Kubo S, Choi W, Liu CL, et al: Posterior instrumentation reduces differences in spine stability as a result of different cage orientations: an in vitro study. Spine (Phila Pa 1976) 30:62-67, 2005

30. Wilke HJ, Jungkunz B, Wenger K, Claes LE: Spinal segment range of motion as a function of in vitro test conditions: effects of exposure period, accumulated cycles, angular-deformation rate, and moisture condition. Anat Rec 251:15-19, 1998

\section{Disclosures}

The authors report no conflict of interest concerning the materials or methods used in this study or the findings specified in this paper.

\section{Author Contributions}

Conception and design: Nagaraja. Acquisition of data: Nagaraja, Palepu. Analysis and interpretation of data: all authors. Drafting the article: Nagaraja, Palepu, Peck. Critically revising the article: all authors. Reviewed submitted version of manuscript: all authors. Approved the final version of the manuscript on behalf of all authors: Nagaraja. Statistical analysis: Nagaraja, Palepu, Simon. Administrative/technical/material support: Nagaraja. Study supervision: Nagaraja.

\section{Correspondence}

Srinidhi Nagaraja, U.S. Food and Drug Administration, Center for Devices and Radiological Health, 10903 New Hampshire Ave., Bldg. 62, Rm. 2210, Silver Spring, MD 20993-0002. email: srinidhi.nagaraja@fda.hhs.gov. 